\title{
The Benefits Of Risk: Teaching Entrepreneurs-To-Be About Risk-Taking
}

Rowena Ortiz-Walters, (E-mail: rowena.ortiz-walters@quinnipiac.edu), Quinnipiac University

\begin{abstract}
This paper reports on an innovative way to actively teach risk-taking to students majoring in entrepreneurship. Specifically, students completed a "Fundraising" assignment that involved different degrees of risk. Below, the qualitative experiences of students in one undergraduate class are shared. Additional, results of a short questionnaire suggested that the students believed the assignment was useful in meeting its objectives. In general, it appears that the fundraising activity was effective in helping students appreciate and understand the multiple roles risk plays in becoming an entrepreneur. Finally, feedback is provided from the students' and professor's viewpoints for improving upon the risk-taking assignment.
\end{abstract}

\section{INTRODUCTION}

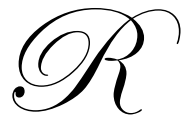

isk is a simple, four-letter word. Its meaning however quite complex: the chance of something going wrong, someone or something hazardous, possibility of loss or injury, statistical odds of danger, putting someone or something in danger, doing something despite danger, and the chance that an investment such as stock will lose value (Merriam-Webster Online).

We all experience risk. But, for entrepreneurs, it's a way of life - it's a matter of venture survival or death, it impacts self-esteem and personal wealth, can interfere with family life and relationships and consume your personal time. So, no one can deny that entrepreneurship is inherently about taking risks.

While entrepreneurship education has tended to focus on teaching students how to develop creative ideas, products and services, exploit opportunities and use networks to secure resources such as capital (see Solomon, Duffy, \& Tarabishy, 2002 for a recent review), far less emphasis has been placed on teaching the "risk component" of entrepreneurship. This is probably the case given that it is so difficult to put students in "real" risk situations so that they can truly appreciate the degree of risk an entrepreneur takes on a daily basis. So the question is, how do we "teach" entrepreneurs-to-be about risk-taking; how do they "actively" learn to weigh the benefits against the risks before deciding to pursue an entrepreneurial career?

This past semester students learned about assessing their risk-taking propensity and how to take calculated risks in a course entitled "Achievement, Risk-taking and the Entrepreneur." This was accomplished through a risktaking assignment. Students designed and implemented a fundraiser (see Appendix 1 for full details). They had a total of 3 weeks in which to design a unique and creative fundraiser (for a complete list of fundraising ideas see Appendix 2) for a charity of their choice (see Appendix 3 for a list of charities and specific amounts collected). They were not allowed to donate money themselves, ask family or professors on campus. The risk came into play in the grading scheme. The assignment was worth $20 \%$ of their grade - if they met the set goal of $\$ 200$ they received an A, if not they received a C for $20 \%$ of their final grade (option A). Or, if they wanted to take a bigger risk for a bigger payoff, they could opt to make the assignment worth $30 \%$ and not have to take the final exam (option B). However, this time the monetary goal was set at $\$ 350$ - if they obtained it they got an $\mathrm{A}$, if not they received a C which counted towards $30 \%$ of their final grade. 
Not surprisingly among a sample of entrepreneurs to be, most students opted for option B. Once they selected an option, all students had to sign and date a sheet of paper so as to formally indicate their chosen risk level. In addition, once all the funds were raised, students had to provide a receipt from their charity to show proof that the funds had been collected and the charities were in fact the beneficiaries. In the sections that follow, the qualitative experiences of students and what they learned about risk in relation to entrepreneurship are shared.

\section{WHAT STUDENTS LEARNED ABOUT TAKING RISKS}

After the project was completed, the students all submitted a reflection paper and made individual minipresentations. In the reflection papers, they shared their thoughts and feelings regarding the assignment as well as their perceptions and new found understanding of the role of risk for entrepreneurs. One of the first lessons learned by several students was related to trusting others and their own capabilities and the risk inherent in doing so.

\section{Lesson \#1: The Risks In Trusting Others And Yourself}

Several students wrote about the tough decision they had to make and how they were unsure if they could pull off the fundraiser, especially for 30\% of their grade. Some had not had experience in such an endeavor and were unsure if they had the appropriate skills necessary to design and implement a fundraiser. In addition, students quickly learned that relying on others involves a high level of risk - you can't always depend on what others promise. Here are some examples and comments from students reflecting the first lesson:

"After receiving this fundraising assignment in class, I had mixed feelings...I was worried. Three weeks to pull off a fundraiser and raise a large sum of money seemed like a daunting task. I have no experience in fundraising and I didn't know where to begin."

“I learned that you can't always count on what people say. It gave me a glimpse into the reality that you are not always going to succeed no matter how hard you try and sometimes you will fail...but sometimes learning from the failure is a benefit itself."

"I felt I took a big risk...and felt nervous every day leading up to the event because I was unsure if people would show up."

"I did take a large risk doing this because people could have decided not to come to this [benefit concert] and gone out to a club or somewhere else.”

"When I was informed of the assignment that required me to raise money for a charity, my first reaction was to say that this was impossible. My basic instinct was to throw in the towel and admit defeat before I had even begun."

"I learned a lot about risk taking in this assignment. I set my goal too low and I feel like I should have gone for the $30 \%$. It really solidified the fact that the higher the risks you take in life the greater the rewards."

"The exercise taught me some valuable lessons on skills that I need to work on: my tolerance for risk and how to judge a situation in terms of risk."

"I learned that I'm a guilty stereotype of entrepreneurs - I always feel like I can do anything. Some times in life we have to realize a poor investment and simply cut our losses.”

"I believe I learned a lot about risk and how it pertains to entrepreneurship through this project. The risk involved in purchasing 500 bracelets was very great because if I was unable to sell them, not only would I get a bad grade but I would also be out that amount of money.” 
"This was the first time I have ever done a project of this caliber in such a short time frame. I was very nervous even on the day of the car wash that I was not going to be able to make all my money back and pull off a successful fundraiser.”

\section{Lesson \#2: The Risks In Making Choices}

Despite the fact that most students went for the riskier option, several students mentioned that they struggled with the options decision. It was a good reminder that they need to conduct a risk/benefits analysis before jumping into any decision and that decision making includes both rational and intuitive components. Some comments related to this lesson included:

"I decided to take the $20 \%$ option and set a goal for 225 dollars. It was a medium target and the risk was high but not too high."

"I chose to raise $\$ 225$ because I felt it was more than the minimum goal set forth for the $20 \%$ option... I also took into account that everyone else in the class would have a fundraiser as well, so in order to compensate for competition I set the goal a little lower."

"I learned you have to weigh all of the options and elements of a task before you implement it...From this I made the decision to take the almost guaranteed 'A' over the possible ' $\mathrm{C}$ ' and play the best odds that were available for me.”

"Looking back I should have taken the $20 \%$ [option] but just like in gambling I like to take the big risk for the big reward. I should have calculated what I would be making, before just choosing the $30 \%$ [option]...”

\section{Lesson \#3: The Risks Involved In Planning}

A number of students planned ahead and had, what they thought, were great ideas for a fundraiser. However, they quickly realized that raising funds is not an easy task, even if it is for a good cause. As such, many reported that after being unsuccessful in their first fundraising attempts, they went to plan B - in other words, they used contingency planning to head off the risks involved. Here are some examples of how students dealt with the issue:

"I posted a sign above the [recycling] garbage can saying Cans for Breast Cancer. After a few days of doing this I realized that it wasn't working too well. The cans contributed only about 40 dollars. I realized I would need to do more and hit certain [other] target markets to reach my goal.”

"I also learned that if one thing fails or doesn't work out how you planned it, its important that you get back up and do it again better.”

“The first thing I learned was to always have a backup plan in case your first method fails.”

"Another thing I learned was not to rely heavily on one thing. I felt confident that I would be able to make my goal...I did not think that other students were going to storm the dorms at the same time as me.”

"The most important thing I learned when undertaking this project is to set realistic goals. In order to eliminate some risk I diversified my streams of income for the project.”

“This is when I needed to come up with a contingency plan because I had wasted a week dealing with several owners to no avail."

“The numbers just wouldn't allow me to do a golf tournament. I would need more time, more players and more money, so I found myself searching for other ways to raise this money.” 


\section{Lesson \#4: The Risks In Raising Capital}

A primary responsibility and task of any entrepreneur is ensuring adequate funds to start and maintain the venture. Students quickly got a lesson in how difficult and risky it is to raise capital and it gave them a new found appreciation for the challenges ahead of them when they do attempt to start-up their own businesses. In addition, they realized the criticality of developing good selling skills when trying to acquire funds. Here is what they shared in regard to this lesson:

"Essentially, what I learned is that in any kind of money raising campaign, whether it be for charity or getting together investors in a business, you have to be extremely proactive. I realized how hard it can be to get money together for any cause and I sympathize with non-profits and struggling entrepreneurs more as a result of having done this project."

"I can attribute this experience to real business. I will need to think in terms of a location when starting my business and will need to analyze the people I am selling to so that I can assess how much they can afford.”

“This project definitely opened my eyes to the business world [particularly selling] and it helped me realize that in fact I do possess entrepreneurial skills."

"This project also made me aware of the stress that an entrepreneur might face when taking big risks with his company my plan didn't work exactly as planned, meaning that not everyone was interested in having their house cleaned...”

"To be honest I am glad I had to do this assignment - I learned time management is crucial, I could never go into the personal selling industry and I have a tendency to spring into things and not think a project through to its end."

"What I have learned from this experience is that people are very reluctant in giving money...I got a few awkward stares from people, probably because they thought I was just a college student trying to make some money for all the wrong reasons."

"I could not delegate enough of my time to work on this project. If I ever become an entrepreneur, the first thing I am going to do is to work on finding good people to surround myself with to absorb some of the stress of owning a business."

\section{Lesson \#5: The Benefits Of Risk}

In total, the class raised over $\$ 12,500$ for a variety of charities. And in the end, this benefit did outweigh the risks! Students showed tremendous excitement in being able to help others. They realized that part of being an entrepreneur is about giving back - making a difference in other people's lives. Likewise, they showed a lot of elation in having set a goal, even a risky one, and being able to accomplish it. Here are just a few examples:

"After counting all of the bills and the change I ended up with 368 dollars! I was extremely happy to reach my goal. It felt good to finally give and it was the first time I actually worked to raise money.”

"I’m glad I did this assignment not just for the grade but for the foundation. I hope my small contribution will help lead to a cure."

"Overall the process taught me a lot about risk taking, made me sweat, and helped a good cause. So in the end, everyone won.”

"I really enjoyed this project. I found it interesting to research the organization I wanted to donate to and ways of raising money...I also extended my network of contacts in the process.” 
"This project taught me that it is important to give back in some form. Our job as entrepreneurs is to leave the world a better place than we found it."

"In the end I felt rewarded. I came out of this feeling satisfied, not simply because of the grade or completing the assignment, but because I could help contribute to a great cause.”

"What I learned from this experience is how to turn an idea into a reality in such a short period of time, which was something I had never done before."

"I did not expect to experience the feeling of satisfaction that I did. I know that I worked hard to raise this money and that the money is being used for something good. This is the first significant contribution I have made on my own to a charity and I feel proud."

"I was thrilled and realized how good it felt to donate to charity. I had been faced with what seemed to be an impossible task and had succeeded.”

In summary, for students risk took on the additional meanings of $\underline{\text { Rewards, }} \underline{\mathbf{I}}$ genuity, $\underline{\text { Service, and }}$ Kinship.

\section{ANALYSIS}

After the class was completed, students were surveyed on a number of issues regarding the course. One area of interest was to assess how important they felt risk-taking was to entrepreneurs and subsequently how useful they found the risk-taking assignment in regard to helping them understand the role of risk in entrepreneurship. Students answered the importance question using a 5 point Likert-type scale ranging from $1=$ unimportant to $5=$ very important. The usefulness question was rated on a 4 point scale $(1=$ not at all; $4=$ to a great extent). All 34 students were surveyed of which 22 submitted a completed questionnaire (65\% response rate).

A Pairwise t-test of the data was conducted and the following interesting findings were discovered. The mean for the importance question was 4.23 while for the usefulness factor it was 3.36 . Moreover, I found there to be a significant difference between the means of the importance question and the usefulness question $(t=6.33, p<.001)$. Overall, the results of the t-test suggest three things: first, students believed the topic of risk-taking was important in entrepreneurship education; second, they rated the assignment related to risk-taking as useful; and third, the usefulness factor was not rated as high as the importance factor indicating the assignment had some room for improvement.

\section{IMPROVING THE TEACHING OF RISK}

One of the primary inputs students provided was in regard to the amount of time given for the assignment. The original assignment was to be completed in three weeks - from inception of the fundraising idea to implementation to goal completion. Instead, some recommended extending the deadline to a one month time period, in particular, 1 week could be dedicated to contacting their charity of choice so that they could obtain fundraising information from the charity (e.g., flyers) and the other three weeks to implementing the activity. This suggestion was made because several students reported in their reflection papers that it took up to 5 days for a charity to get back to them with the appropriate materials at which point they had used up about a $1 / 3$ of their time to complete the project; in some cases charities did not get back to them and they found themselves starting the whole process all over again.

As a result of this feedback, the amount of time given for completing this assignment should be considered carefully. The decision to provide only 3 weeks was made because the time-frame was viewed as part of the "risk" component of the assignment providing a strict deadline in which to complete the project. If too much time is given, this may negate the risk effects of the assignment. If the situation calls for it, perhaps a month could be reasonable but, certainly not much more time than that. The students need to learn that as an entrepreneur there will be times when they need to raise capital quickly or make difficult and important decisions within a short time frame; the three to four week time frame design should facilitate this goal best. 
The other piece of feedback received was in relation to when the project was rolled out during the semester. The assignment was given later rather than early in the semester to give students time to appreciate the nature of entrepreneurship first, through various other assignments and lectures. However, students recommended that in the future it should be assigned much earlier given that toward the end of the semester students get busier with mid-terms and exams. Also, without realizing it, one of the weekends during the time of the assignment turned out to be a holiday so in the future both of these issues regarding time should be given careful consideration when rolling out the project.

In the original assignment, students were given two risk levels or options to choose from. However, some commented that changing the grading rubric to include more risk options would have been helpful and made the assignment even more interesting as there would be greater variance in the degree of risk students were willing to assume. This could turn out to be a very interesting strategy but it would need to be adapted to the specific course being taught. Depending on the other grading components of the class, one could increase the risk options to three and try level 1 at $10 \%$, level 2 at $20 \%$ and level 3 at $30 \%$.

Finally, a few students mentioned that they would have preferred if the assignment were a group project rather than an individual project. They felt they could have been more successful and raised more money if they went into it as a group; for example, once the fundraising idea was generated by the group different roles could be assigned to individual group members so as to give them a better chance of meeting their monetary objective. The original assignment was designed as individual assignment because this is probably the best way to gauge each individual entrepreneur-to-be's risk tolerance, which will probably be masked if conducted as a group. However, the assignment certainly could be adapted to the group level and different dimensions of the venture team could be introduced and explored. If a group perspective is used, it is recommended that the monetary level of the assignment be increased proportionately as to still make it a risk-oriented assignment.

\section{CONCLUSION}

This brief paper reports on undergraduate students' experiences with an activity focused on taking risks in an entrepreneurial context. Overall, the findings indicate that more needs to be done in the area of risk-taking and entrepreneurship education. It is hoped that by sharing these experiences, others, such as academics and practitioners, will be stimulated to venture out and try new innovative ways to teach risk-taking to students. A special focus on improving upon this current method would be useful in addition to finding other activities to teach students at the graduate level.

\section{APPENDIX 1}

\section{The Fundraiser: Risk And Entrepreneurship}

You are charged with designing and implementing a fundraiser. This activity has two purposes.

1. $\quad$ First, to exercise your creativity-relevant skills by designing an original fundraiser idea.

2. Second, to see what role risk plays in the personality of an entrepreneur - i.e. how much of a risk-taker are you.

The activity

1. Pick a charity of your choice. It can be local or national - just make it one that is meaningful to you personally.

2. Choose one of two grading options of how much money you would like to raise for your chosen charity. You must decide on one of the two grading options before you begin implementing the fundraiser and sign a contract.*

3. Design the fundraiser (individually). You have 1 week to do this. Be as creative as possible - this is your opportunity to show your innovative "stuff." 
4. Implement the fundraiser and try to meet your goal. You have 3 weeks to work toward your goal (Caution: you get an automatic "0" for the assignment if you do not meet your goal but say you do by putting in the difference from your own funds - so don't even try it!)

5. All funds will be delivered to the appropriate charity. Receipts should be given to the professor.

6. Write a progress report ( 2-3 pages, typed) in which you reflect upon this experience. Include a P\&L statement of all expenses and income generated.

7. Each student will make a brief PowerPoint presentation (2-3 slides max) about what they learned from the project.

\section{GRADING*}

\section{Option 1 - Less Risky}

The assignment is worth $20 \%$ of your grade. Here is the breakdown:

1. $10 \%$ for reflection report and degree of creativity in designing the fundraiser.

2. $10 \%$ for goal completion - if you raise $\$ 200$ you get an $\mathrm{A}$; if you do not meet this goal you get a C).

\section{Option 2 - More Risky}

The assignment is worth $30 \%$ of your grade. Here is the breakdown:

1. $\quad 10 \%$ for reflection report and degree of creativity in designing the fundraiser.

2. $20 \%$ for goal completion - if you raise $\$ 400$ you get an $\mathrm{A}$ and, you do not have to complete the Final for the course; if you do not meet this goal you get a C).

\section{Caveats}

1. You cannot ask professors or administrators for donations.

2. If you go outside the school, you must not use the University’s name.

\section{APPENDIX 2}

\section{Fundraising Ideas}

1. Tag sale

2. Bake sale

3. Donation cans

4. Car wash

5. Dorm Storm

6. $\quad$ Candy Bags

7. Selling coffee

8. Barbecue

9. Hockey Skate Sharpening

10. Value card

11. Tire recycling

12. Hiking and first aid seminars

13. Golf tournament

14. Bracelets (like the Armstrong bands)

15. Softball tournament

16. Recycling cans

17. Easter eggs

18. Benefit concert 
19. Cutest Pet contest

20. Spring cleaning

21. Animal education

22. Raffle

23. Asking for donations at school-related sporting events

24. Sale of flowering tress, oak trees or Colorado blue spruces

25. Selling baseball tickets

\section{APPENDIX 3}

\section{Charities And Specific Dollar Amounts Raised}

1. $\quad$ Autism Spectrum Resource Center, Inc. (\$240)

2. National Children’s Cancer Society (\$388)

3. Jimmy Fund (\$200, \$400)

4. Schooner, Inc. $(\$ 215, \$ 433)$

5. Meriden Humane Society $(\$ 500)$

6. $\quad$ Saint Jude Children’s Research Hospital (\$502.12)

7. National Ehlers Danlos Syndrome Foundation (\$607)

8. Connecticut Farmland Trust (\$318)

9. National Arbor Day Association (\$470)

10. Partnerships Center for Adult Day Care, Inc. (\$800, \$350, \$350)

11. Habitat for Humanity (\$103.29, \$109)

12. Andre Agassi Charitable Foundation (\$366)

13. The Friend's Project (\$628)

14. Dana Farber Institute (\$112.87)

15. American Heart Foundation (\$350)

16. Fidelco Guide Dog Foundation (\$300)

17. American Cancer Society $(\$ 512.37, \$ 367, \$ 510$ )

18. The Children's Center of Hamden (\$253.47)

19. American Diabetes Association (\$500)

20. Susan G. Komen Breast Cancer Foundation (\$368)

21. Autism Speaks (\$355)

22. Friends of Animals (\$430)

23. Camp Sunshine (\$381)

24. Corpus Christi Food Pantry (\$364.80)

25. The Jorge Posada Foundation (\$370)

26. American Liver Foundation (\$350)

Total $=\$ 12,503.92$

\section{REFERENCES}

1. Merriam-Webster Online. http://www.m-w.com/dictionary/risk

2. Solomon, G. T., Duffy, S., and Tarabishy, A. (2002). The state of entrepreneurship education in the United States: A nationwide survey and analysis. International_Journal of Entrepreneurship Education, 1 (1), 65-86. 